\title{
A política pública para os serviços urbanos de abastecimento de água e esgotamento sanitário no Brasil: financeirização, mercantilização e perspectivas de resistência
}

The public policy for urban water supply and sanitation
services in Brazil: financialization, commodification
and resistance perspectives

Ana Lucia Britto Sonaly Cristina Rezende

\section{Resumo}

Este artigo busca analisar a política pública de abastecimento de água e esgotamento sanitário durante as gestões do Partido dos Trabalhadores, entre 2007 e 2014, identificando, nos instrumentos da política, uma ambiguidade entre uma lógica mercantilizadora e uma lógica do saneamento como direito social. São examinados o crescimento das empresas privadas de saneamento no período, evidenciando suas características, e as mudanças recentes, com entrada do capital internacional. Finalmente, são apresentados, como o contraponto ao que vem ocorrendo no Brasil, casos internacionais de retomada da gestão pública, que demonstram que a privatização não é a única alternativa, e que é possível conciliar eficiência e uma lógica de saneamento como direito social.

Palavras-chave: saneamento básico; política pública; privatização, direito social; gestão pública.

\begin{abstract}
The article aims to analyze the public water supply and sanitation policy during the Brazilian Labor Party's administrations between 2007 and 2014, identifying, in the policy instruments, an ambiguity between a commodification logic and a logic of sanitation as a social right. It examines the growth of private sanitation companies in the period, showing their characteristics, and the recent changes promoted by the entry of international capital. Finally, it presents, as a counterpoint to what has been happening in Brazil, international cases of public management resumption, which demonstrate that privatization is not the only alternative, and that it is possible to reconcile efficiency and a logic of sanitation as a social right.
\end{abstract}

Keywords: basic sanitation, public policy, privatization, social right, public management. 


\section{Introdução}

Neste artigo, busca-se traçar o perfil das pressões mercantilizadoras sobre os serviços urbanos de abastecimento de água e esgotamento sanitário no Brasil, recuperando as políticas públicas implementadas entre 2007 e 2014, identificando-se projetos e ações promovidos pelos governos federal e estaduais, contrapondo-os às políticas de resistência do serviço de saneamento como serviço público identificadas em determinados países da Europa.

Para construir nosso argumento, recorremos ao referencial analítico que trata das lógicas mercantilizadoras na gestão das águas, em geral, e dos serviços de abastecimento de água e esgotamento sanitário, em particular, com base em autores da ecologia política da água e do campo da geografia crítica; recorremos, também, ao referencial que trata da análise da política pública de saneamento.

No que diz respeito às lógicas mercantilizadoras na gestão dos serviços urbanos de água, o argumento central é que a água é um recurso escasso que deve ser gerido de forma eficiente. Na lógica neoliberal, a melhor maneira de assegurar essa eficiência é através de uma política de preços adequada e de gestores capazes de aplicá-la: as empresas privadas.

Para examinar as lógicas mecantilizadoras na gestão da água, recorremos aos trabalhos de Loftus (2009) e de Swyngedouw (2004), na perspectiva da ecologia política da água. Para os autores, a injustiça na distribuição da água é um ponto de partida. Ao invés de encontrar respostas em promessas ou soluções técnicas, a ecologia política procura politizar o entendimento da distribuição de água (Loftus, 2009). Swyngedouw mostra que a água, além de ser um elemento vital, possui um vasto significado no campo social, intelectual e cultural e internaliza relações de poder. Definindo o ciclo urbano da água, o autor mostra que ela é necessariamente transformada, metabolizada, em termos das suas características físico-químicas e, também, em termos das suas características sociais e dos significados culturais e simbólicos que lhe são atribuídos. No caso das cidades capitalistas, ou das cidades em que as formas de troca se estabelecem, sobretudo, pelas relações de mercado, a água também faz parte da circulação de dinheiro e capital (Swyngedouw, 2004).

A lógica da mercantilização da água, via sua inserção na circulação de dinheiro e capital, busca transformar esse recurso num commodity, gerando dependência a uma "política de preços" e sendo gradualmente submetida aos "processos de financeirização" e ao chamado "mercado de futuros" (Bruckmann, 2011, p. 212). Para a autora, essa visão é defendida por representantes de empresas privadas de água que concentram $75 \%$ do mercado mundial.

A circulação da água também pode ser entendida como governança urbana da água pautada no processo de decisão e de implementação sobre a alocação, o uso, o tratamento e a reciclagem de água urbana. $A$ análise da governança urbana da água enfatiza atores e instituições que interagem na sua gestão. DetaIhando essa perspectiva, Castro (2007) ressalta a perspectiva da governança como processo conflituado de interações entre governo, grandes empresas, partidos políticos, organizações da sociedade civil, representando interesses setoriais (sindicatos de trabalhadores e ONGs) 
e agências internacionais (instituições financeiras internacionais e outros agentes do processo de governança global). Esses atores estão envolvidos em debates contínuos e em confrontos sociopolíticos sobre como governar serviços essenciais relacionados à água, por quem e para quem, representando o cerne do processo de governança democrática da água, caracterizado pelo diálogo e pela negociação, e também por crescente incerteza e por conflitos sociais e políticos prolongados (ibid.).

Podemos afirmar que a governança da água é determinada pelo que Heller e Castro (2007) denominam condicionantes sistêmicos: "processos socioeconômicos, políticos e culturais que estruturam e determinam as opções de políticas públicas".

Em uma análise da economia política da água, Swyngedouw, Kaika e Castro (2016) mostram que, no cenário internacional, a organização dos sistemas urbanos de abastecimento de água pode, de forma geral, ser dividida em quatro estágios.

0 primeiro vai até a segunda metade do século XIX, quando a maioria dos sistemas urbanos de água consistia de empresas privadas relativamente pequenas para o fornecimento de água a uma parcela restrita da população. A qualidade da água era variável, resultando em um padrão de abastecimento altamente estratificado, com a atuação das empresas visando, essencialmente, à geração de lucros para seus investidores.

0 segundo é marcado por um processo de municipalização dos serviços promovida, principalmente, pela preocupação causada pela deterioração das condições ambientais e pelo aumento das exigências de salubridade urbana. A rentabilidade é, nesse contexto, uma preocupação secundária, tendo em vista que se pode contar com subsídios oriundos da receita gerada por impostos públicos (seja no governo local, seja no nacional), e os sistemas de abastecimento de água tendem a se consolidar, expandindo a cobertura doméstica integrada a um sistema de esgoto, com disposição final, mesmo que sem tratamento.

0 terceiro estágio inicia-se após a I Guerra Mundial, quando os setores de saneamento, eletricidade e telecomunicações se tornam parte de uma preocupação crescente. Os Estados Nacionais passam a ter um papel central na regulação, no controle e nos investimentos, no contexto de uma política econômica e social fordista-keynesiana.

Buscando enxergar a evolução das ações de saneamento no Brasil, na vertente da discussão de Swyngedouw, Kaika e Castro (2016), percebe-se que a evolução das ações coletivas de saneamento, desde as primeiras vilas, o surgimento das primeiras cidades e polos econômicos e de poder, revela, na origem, a esfera privada atuando no setor, mas sem se constituir uma atividade lucrativa. Após a vinda da Corte Portuguesa para o Brasil, ao fim do primeiro quartil do século XIX, adotou-se a responsabilização municipal ante a questão sanitária. Foi com o aumento da população e seu adensamento nas principais cidades do Império, em meio à insalubridade ambiental e às doenças, que surgiu o debate pautado na teoria do contágio e, decorrente deste, a defesa da existência da interdependência sanitária, ganhando destaque a premissa de que o microrganismo transmissor da doença seria democrático, escoIhendo suas vítimas indistintamente (Hochman, 1998; Lira Neto, 1999). Tal compreensão resultou em que o poder público se posicionasse 
diante das demandas sanitárias e, dada a sua incapacidade técnica de assumir diretamente a gestão e a prestação dos serviços, no final do século XIX e início do XX, transferisse à iniciativa privada tal prerrogativa. Segundo Costa (1994), assumiram esse papel de maneira hegemônica as companhias inglesas, instalando-se em cidades estratégicas para a economia nacional, como a cidade portuária de Santos. A atuação dessas companhas foi breve, na maior parte dos locais atendidos, graças a referida qualidade variável e abastecimento de água estratificado, mencionados por Swyngedouw, Kaika e Castro (2016), que deram o tom a essas concessões, juntamente com o mote principal de geração de lucros para seus investidores. Tendo ficado constatado o fracasso do setor privado nesse ramo (Costa, 1994), foi consenso de que apenas o Estado poderia mobilizar os recursos necessários para viabilizar a complexa infraestrutura sanitária requerida (Rutkowski, 1999).

0 poder público assumiu, então, a prerrogativa de cuidar do saneamento com a experiência fracassada das privadas. Delineou-se, dessa forma, o segundo estágio mencionado por Swyngedouw, Kaika e Castro (2016), com a municipalização dos serviços apoiada pelo governo federal, resultando em discussões sobre a titularidade local e a intervenção por parte das unidades da federação, no caso de os municípios não estarem aptos a resolverem problemas de interesse regional. Nessa fase, ações são implementadas com recursos oriundos dos impostos públicos, e os sistemas de água e esgotos saem do circuito das capitais por meio da administração direta do poder público municipal.
Essa nova configuração política que se consolidou no território brasileiro, no início do século $X X$, com o passar dos anos, reverteu-se em práticas de corrupção e clientelismo que refletiam no mau funcionamento dos sistemas. Em um novo contexto, no entorno da Segunda Guerra Mundial, e tendo em conta a presença dos norte-americanos no Brasil, inicia-se uma proposta para a gestão pública do saneamento (Brown, 1976). As relações entre o Brasil e os EUA intensificaram-se com a criação do Serviço Especial de Saúde Pública (Sesp), resultando no auxílio técnico e financeiro dos EUA ao Brasil (Peçanha, 1976), havendo, por traz dessa ação, a pretensão de se explorar recursos minerais e vegetais de áreas de especial interesse, como na região do médio rio Doce. Ali, era frequente a presença de engenheiros norte-americanos, que inovaram ao introduzir um modelo de gestão público vinculado ao ente municipal, mas com autonomia para a gestão dos sistemas (Rezende e Heller, 2008).

Até a década de 1950, as diretrizes para os setores saúde e saneamento eram bastante relacionadas. A partir daí o caminho da saúde distanciou-se do saneamento, e este setor se volta para a gestão regionalizada, sustentada no modelo de sociedades de economia mista, representada pelas companhias estaduais, que passaram a atuar, já na década de 1960, prioritariamente no abastecimento de água. Esse modelo mostrou, desde sua instalação, grande alinhamento com os propósitos pré-capitalistas que aceleraram o ritmo da industrialização no País. Nesse contexto, surgiu o primeiro plano de saneamento do País, o Planasa, em grande medida voltado para 0 atendimento de áreas de especial interesse 
econômico e para o fomento a meios de produção capitalista (ibid.).

Ao se buscar cotejar elementos descritos por Swyngedouw, Kaika e Castro (2016), para o cenário internacional, na terceira etapa de desenvolvimento da organização dos sistemas de abastecimento de água, com a trajetória brasileira, observam-se experiências comuns ou semelhantes. Em meio a outras necessidades básicas intrínsecas ao sistema capitalista, num primeiro plano, figuravam as ações voltadas para 0 atendimento das atividades industriais e das demandas domiciliares a elas relacionadas. A escolha das Companhias Estaduais de Saneamento Básico (Cesb) como agentes do Plano foi determinante para a consolidação desse modelo de gestão e sua supremacia no abastecimento de água, ação favorecida quando comparada ao esgotamento sanitário. Sua lógica de criação, voltada para os rápidos ganhos de escala no atendimento por redes de água, tem um paralelo com a lógica descrita pelos autores. Como no plano internacional, o Estado brasileiro também incorpora a política econômica e social fordista-keynesiana, introjetada aqui em um contexto de ditadura militar no qual o Estado usava de instrumentos coercitivos para alcançar seus objetivos, coadunando com os ideais imperialistas norte-americanos, impondo aos municípios à concessão dos serviços às Cesbs, caso estes desejassem acessar os recursos do Planasa.

Swyngedouw, Kaika e Castro (2016) mostram que a quarta e mais recente fase começa com a recessão global de 1970, associada ao declínio no crescimento econômico liderado pelo Estado, com posterior transição para um modelo econômico pós-fordista ou de formas mais flexíveis de desenvolvimento econômico e de liderança do Estado. Essa fase é marcada por uma mudança nas relações entre setor público e setor privado no campo do saneamento. A crise econômica levou a crescentes dificuldades orçamentárias para os governos nacionais e, por vezes, para os locais, resultando na redução de despesas com serviços públicos, incluindo aí os serviços de saneamento, preterindo-se investimentos subsidiados no setor da água, sendo privilegiados investimentos para apoiar setores industriais endividados. Ao mesmo tempo nos países centrais ocorreu um envelhecimento das infraestruturas combinado com uma demanda crescente por água, gerando ainda maior pressão sobre os orçamentos públicos. Surgem, então, as soluções apoiadas no recurso ao capital privado como forma de enfrentar a crise do modelo fordista.

A desterritorialização dos mercados financeiros, acompanhada da ampliação da participação privada na prestação dos serviços; 0 desenvolvimento de uma gestão orientada por uma lógica de negócios ou de mercado, em sintonia com as estratégias para a geração de lucro privado são aspectos comuns nesse período. Os investidores começaram a explorar novas fronteiras para o investimento de capital: "a água surge como uma possível nova fronteira a ser explorada, com o forte potencial de transformar $\mathrm{H}_{2} \mathrm{O}$ em dinheiro e ganhos privados" (ibid., p.17)

Por outro lado, Swyngedouw, Kaika e Castro (2016) afirmam que o processo não ocorre sem resistência; em regimes democráticos, movimentos sociais e sindicais colocaram barreiras a essas mudanças. Particularmente em contextos em que grupos da sociedade civil mobilizados por questões ambientais se tornaram mais visíveis e influentes, os sistemas de 
governança tinham que se tonar mais sensíveis a essas questões.

0 efeito combinado dos processos e dinâmicas descritos provocou uma mudança mais ou menos radical (com diferentes graus de intensidade em diferentes países), tanto na prática como no nível ideológico/discursivo, de modo que o setor da água, convencionalmente dirigido e controlado pelo Estado, teve que entrar em sintonia com as forças de mercado globalizado e com os imperativos de uma economia privatizada e competitiva (Kallis e Coccossis, 2001, apud ibid.). Além disso, empresas de saneamento tornaram-se parte de empresas globais, com base em locais diversos ou de conglomerados multisserviços, normalmente globais.

Podemos afirmar que a política de saneamento no Brasil se encontra nessa quarta fase, na qual avanços e retrocessos são identificados em dois sentidos: saneamento como direito e saneamento na perspectiva de uma política neoliberal, conectada a financeirização e mercantilização da cidade. Esses avanços e retrocessos são atribuídos à governança conflituada desses serviços, fruto das pressões, por um lado, dos movimentos sociais, sindicais e setores mais progressistas ligados à gestão dos serviços e, por outro, dos atores ligados ao setor privado e de atores públicos alinhados à lógica mercantil e serão examinados a seguir.

\section{A política pública do governo federal entre 2007 e 2014}

Buscamos nessa parte do texto examinar a política pública federal de saneamento no segundo mandato do Governo Lula e no Governo Dilma, procurando evidenciar leis e regras adotadas, relações entre os atores, conflitos estabelecidos na perspectiva do saneamento como um direito social e na perspectiva do saneamento inserido na lógica de financeirização e mercantilização.

Os dois governos apresentaram, tanto no discurso como nas ações, perspectivas de avanço do saneamento como direito social. Nesse sentido identificamos: (1) a aprovação da lei n. 11.445/2007 e de seu decreto de regulamentação, de 2010; e (2) a promoção do controle social e o funcionamento regular do Conselho Nacional das Cidades (ConCidades), e das Conferências Nacionais das Cidades. A lei do saneamento pauta-se em princípios de direitos sociais que apontam para a necessidade de priorização de planos, programas e projetos que visem a implantação e ampliação de serviços e ações de saneamento nas áreas ocupadas por população de baixa renda. Busca assegurar 0 atendimento da população do campo, da floresta e das águas, em áreas rurais com aglomerações ou dispersões populacionais, considerando seus aspectos socioculturais como determinantes de soluções de saneamento.

Ainda no campo dos avanços, identificamos a elaboração do Plano Nacional de Saneamento Básico (Plansab), prevista na lei n. 11.445/2007, e os princípios explicitados no plano: universalidade e equidade. Elaborado entre 2009 e 2011, o plano foi submetido à Consulta Pública, em 2013, e aprovado pela Presidente Dilma em novembro de 2013 (decreto n. 8141, de 20 de novembro de 2013).

No âmbito dos financiamentos, a instituição do PAC 1 e PAC 2 elevou os investimentos a um novo patamar, viabilizando recursos para que a política pública pudesse caminhar 
no sentido da universalização. 0 PAC 1 previa investimentos de 40 bilhões em quatro anos e um volume contratado, em 2007, de 10,4 bilhões, mais que o dobro do contratado em 2006. 0 Governo Dilma deu continuidade ao PAC através do PAC 2, lançado em março de 2010, prevendo investimentos da ordem de 45,8 bilhões de reais em saneamento básico, sendo 41,8 bilhões disponibilizados por meio do Ministério das Cidades e outros R $\$ 4$ bilhões via Fundação Nacional de Saúde. Observa-se ainda dentro do PAC o Programa de Urbanização de Assentamentos Precários, que incluía obras de implantação de sistemas de saneamento básico.

Como aspectos positivos do PAC destacam-se a previsibilidade e a regularidade na oferta de recursos, o que possibilitou o estabelecimento de condições favoráveis para o planejamento setorial, fator de extrema relevância em função das características institucionais de gestão descentralizada dos serviços públicos de saneamento no Brasil. No âmbito do PAC 2, uma parte dos recursos foi destinada à elaboração de planos municipais de saneamento básico via seleção pública do PAC. Como aspectos negativos, observa-se que a distribuição dos recursos não foi efetivamente debatida no ConCidades, desrespeitando-se processos democráticos e de controle social construídos em torno da elaboração da política de saneamento.

Nesse sentido, vale destacar o embate ocorrido em 2013, em torno da aprovação da portaria n. 280, de 25 de junho de 2013, pelo Ministério das Cidades, que possibilitou o acesso de recursos do Orçamento Geral da União (OGU) pelo setor privado para empreendimentos de saneamento básico do PAC. O Conselho Nacional das Cidades, em sua Câmara Técnica do Setor, resolveu pela revogação dessa aprovação, o que não ocorreu.

Até então, nos casos em que a operação ou a prestação dos serviços de abastecimento de água e/ou de esgotamento sanitário de município beneficiado pelos recursos do PAC fossem delegadas para empresa ou instituição da qual o Poder Público não detivesse maioria de ações com direito a voto, durante a vigência do respectivo instrumento de repasse, o desembolso dos recursos do PAC deveria ser suspenso (item 19.4 do referido manual). Por meio da portaria n. 280, previu-se exceção a tal suspensão: ela não seria aplicada aos casos em que a operação ou a prestação de serviços tivesse sido transferida por contrato de concessão na modalidade não onerosa (sem cobrança pelo Poder Público de valor de outorga), firmado sob o amparo das leis n. 8.987/1995 - Lei de Concessões -, e n. 11.079/2004 - a Lei de PPPs. Assim, a partir de 2013, recursos do PAC passaram a ser disponibilizados para empresas privadas que detinham concessões de saneamento.

Verificamos, portanto, ao longo dos Governos Lula e Dilma, avanços no sentido de se construir uma política universalista e democrática, mas também um movimento através do qual a participação privada e a lógica de mercantilização no saneamento saem fortalecidos, beneficiados pelo acesso aos recursos públicos.

Chama a atenção, nesse sentido, a configuração da Saneatins, cujo controle, em 2011, passou ao Grupo Odebrecht através da subsidiária Foz do Brasil. Toda a composição acionária privada da Saneatins ( $76,52 \%$ do total) foi transferida para a recém-criada Foz Centro Norte. Com a associação, a Foz do Brasil agregou um milhão de habitantes, passando 
a operar em 125 municípios do Tocantins e em cinco do Pará.

Dados de 2015, do SNIS, mostram que cinco capitais estaduais: Manaus, Palmas, Campo Grande, Cuiabá e a cidade do Rio de Janeiro (zona Oeste) apresentam concessão privada de serviços de saneamento. Outras cidades importantes em seus respectivos estados também possuem concessão privada de serviços de saneamento: Cachoeiro de Itapemirim (ES), Niterói, Campos dos Goytacazes, Nova Friburgo, Petrópolis e Resende, no estado do Rio, e Sinop (MT). No Maranhão, duas das três cidades que compõem a ilha de São Luiz, Paço de Lumiar e São José de Ribamar, contam com serviços prestados pela Odebrecht Ambiental (Brasil, 2016).

Algumas companhias estaduais consolidaram o processo de abertura de capital iniciados em períodos anteriores: Sabesp, Copasa e Sanepar. Nas duas primeiras, os dois estados detêm a maioria do capital, São Paulo, 50,3\% e Minas Gerais 51,13\%, sendo o restante das ações fragmentado entre pequenos acionistas nacionais e internacionais; a composição acionária atual da Sanepar é a seguinte: Estado do Paraná, 51,4\%; Dominó Holdings, 12,2\%; Copel, 7,6\%; Fundo garantidor PPP-PR, 7,3\%; Andrade Gutierrez Concessões, 2,1\%; City Group ventures, 2,0\%; prefeituras municipais, $0,5 \%$, e outros, $16,9 \%$. Além disso, diferentes formas de associação com o capital privado se concretizam.

0 setor privado também se consolida cada vez mais como ator capaz de representar seus interesses junto ao Governo Federal, através da Abcon-Sinduscon, que congregam empresas privadas prestadoras de serviços públicos de água e saneamento básico, bem como outras empresas dos setores da construção civil e de infraestrutura, marcando como posição a de quererem:

[...] ser reconhecidos pela sociedade, pelos agentes do setor de saneamento e pelos governos como entidades que primam pelo padrão e qualidade de sua representação institucional, baseadas em princípios éticos e idôneos, em prol do desenvolvimento do setor, promovendo as operações privadas que atuem com eficácia, transparência, equidade e universalidade. ${ }^{1}$

A participação da Abcon-Sinduscon junto ao ConCidades e no processo de elaboração do Planasb foi uma constante. Em 2007, é criado o Instituto Trata Brasil, uma Oscip (Organização da Sociedade Civil de Interesse Público) que tem como associado o setor empresarial privado interessado em questões do saneamento. 0 Trata Brasil vem ganhando grande legitimidade junto à mídia e aos governos estaduais, como entidade produtora de estudos qualificados.

Além disso, como assinalam Swyngedouw, Kaika e Castro (2016), o processo não ocorre sem resistência: movimentos sociais e sindicais colocaram barreiras a essas mudanças. No Brasil destaca-se a importância da articulação dos movimentos sociais e do movimento municipalista mais progressista, representado, sobretudo, pela Assemae, (Associação dos Serviços Municipais de entidade) organizada em Regionais em todo o Brasil, no freio às pressões mercantilizadoras. Dentro do ConCidades, esses dois grupos de atores formam uma coalização em torno de uma visão de saneamento como direito social. Tal coalizão foi de fundamental importância para o apoio ao Decreto de regulamentação da lei n. 11.445/2007. 
A Assembleia da Assemae, realizada em junho de 2010, em Uberaba, teve como tema "Avançar no Saneamento é Garantir a Cidadania". Comemorativa dos seus 25 anos de atuação, contou com a presença do Presidente Lula e do Ministro das Cidades, Márcio Fortes. Era a primeira vez que um presidente da república participava de uma Assembleia da Assemae, evento que ocorre anualmente, indicando um reconhecimento pelo Governo Federal da pauta das entidades mais progressistas do setor.

Nessa mesma época, a versão preliminar do Plansab já estava em fase final de elaboração, porém a consulta pública só ocorreu em 2013. Para os setores progressistas do saneamento, o Plansab representou um avanço progressista do setor; ele introduziu uma cultura de planejamento, dando maior transparência e racionalidade à alocação dos investimentos federais, ainda marcada por emendas parlamentares de caráter clientelista; fortaleceu, através de linhas de financiamento específicas para capacitação e planejamento, os gestores e prestadores públicos, a regulação e o controle social, princípios da lei n. 11.445/2007.

Mesmo sendo defendido pelo Governo Federal, o Plansab foi alvo de críticas da coalizão representada pela Aesbe, Abes e Abcon/ Sinduscon. Para a Aesbe, o Plano:

[...] exacerba na quantidade de estratégias listadas, as apresenta de forma generalista e não prioriza diretrizes, o que confere ao documento um caráter muito mais intencional que diretivo. Apesar de 0 plano inegavelmente inovar ao promover no setor a prática do planejamento, ação pouco usual na área, ele peca em não estabelecer com clareza o caminho para a almejada universalização do saneamento, isso tem provocado dúvidas quanto à implementação do plano. (2014)

A entidade destaca, ainda, haver incerteza de alocação de recursos, pelo fato de os cálculos dos valores necessários à universalização dos serviços terem sido realizados com base em um cenário muito positivo (inflação de 3,5\% ao ano e taxa de crescimento anual de $4 \%$, até 2033). Além disso, evidencia a dificuldade de implementação das macrodiretrizes decorrente da diversidade econômica e social e dos diferentes níveis de capacidade administrativa apresentados pelos mais de 5.500 municípios brasileiros; e critica o número e a complexidade das 138 estratégias que visam a materializar as metas previstas para 2033. Segundo a Aesbe:

0 conjunto dessas estratégias, de tão amplo, demanda por parte do governo federal maior ordenamento de suas estruturas administrativas; o que exigirá do governo federal uma extraordinária capacidade de harmonizar a atuação dos entes e atores mencionados no documento. $(2014$, pp. $23-24)$

Para a Abcon/Sindcon, o Plansab é uma referência do déficit do setor, e, caso sejam mantidos os atuais níveis de investimento no saneamento, a meta de universalização estabelecida só será atingida em 2055. Assim, para que a universalização se torne realidade, em 20 anos, o Brasil precisa investir ao menos R\$ 15 bilhões por ano no saneamento, mais do que o dobro da média investida nos últimos dez anos. Na visão da Abcon, atingir esse patamar de investimento é um desafio que só será possível vencer com a complementaridade entre os recursos dos setores público e privado. No $26^{\circ}$ 
Congresso da Abes, realizado em Porto Alegre, em 2011, Paulo Roberto Oliveira, presidente da Abcon, fez críticas à versão preliminar do plano (anterior à consulta pública de 2012): "somente nas macrodiretrizes do plano é que se faz menção às contribuições potenciais do privado, que deveriam ser mais bem exploradas nas estratégias, nos programas e nas ações".?

Tanto as argumentações da Aesbe quanto as da Abcon são pautadas por uma visão empresarial do saneamento, ressaltando aspectos em que o Plansab poderia contrariar essa visão. Ambas defendem a promoção de subsídios à população que realmente precisa e que se enquadre dentro dos critérios estabelecidos para outros benefícios sociais do governo; e a inclusão do subsídio para o saneamento na política social do Governo Federal. Os subsídios seriam de responsabilidade do Estado, garantindo-se, portanto, o pagamento dos usuários de baixa renda, eliminando-se a inadimplência e também a lógica de subsídios cruzados. Não está dito, mas implícito, que os lucros auferidos na prestação dos serviços não seriam prejudicados por uma possível inadimplência da população de baixa renda. Vale lembrar que a Abcon defende como modelo adequado o de subsídios aos usuários de baixa renda da empresa chilena Aguas Andinas. É adotada a fórmula segundo a qual o Estado concede subsídios destinados a valores de conta que ultrapassem 2 a $3 \%$ da renda familiar das famílias de baixa renda. Os critérios para atribuição do subsídio são o custo da conta e a renda familiar em diferentes regiões do país. Esse subsídio cobre apenas parte do consumo do usuário, e o Estado paga diretamente ao prestador a parte da conta que é subsidiada, sem transferência de dinheiro para o beneficiário. Ele é cancelado se houver falta de pagamento da parcela não subsidiada. Evidentemente esse modelo garante o retorno do investimento à empresa privada.

\section{0 papel cada vez mais proeminente do setor privado e da lógica mercantil versus o enfraquecimento do setor público}

No período entre 2011 e 2015, houve um efetivo incremento da população atendida por operadores privados, considerando-se as diferentes formas de contratos: concessão total, concessão parcial, PPP, etc. Dados da Abcon de 2015 indicam que são 304 municípios atendidos pelo segmento privado, distribuídos por diversos estados. A maior parte das concessões privadas está em cidades que possuem menos de 50 mil habitantes. Isso se explica pelo número expressivo de municípios atendidos pela Saneatins, com menos de 50 mil habitantes; das 47 concessões à companhia, apenas três municípios têm população superior a 50 mil habitantes: Palmas, Araguaína e Gurupi (Abcon e Sindcom, 2015).

A participação privada também se faz presente em projetos nas metrópoles, como a PPP entre a Sabesp e a CabSpat (empresa formada pela Galvão Engenharia S.A. e pela Companhia Águas do Brasil), dos Sistemas AltoTietê e São Lourenço, em São Paulo, para a ampliação da produção de água; o Cidade Saneada, na Grande Recife (PPP para construção de sistemas de coleta e tratamento de esgotos na RM de Recife, entre a Compesa e a Foz do Brasil Odebrecht Ambiental); a concessão 
do sistema de coleta e tratamento de esgoto nas cidades do Rio de Janeiro (Região Oeste AP5) e Maceió; a PPP feita entre a Copasa e a Odebrecht Ambiental para o aumento da produção de água na bacia do rio Manso, que atende a RMBH); além das concessões em três importantes capitais do País (Campo Grande, Cuiabá e Manaus) (Abcon Sindcom, 2015).

No mesmo período, outras companhias estaduais deram início a processos de abertura de capital. Em 2011, o governo do Estado de Santa Catarina decidiu negociar, na bolsa de valores, 49\% das ações da Companhia de Água e Saneamento (Casan). As ações da Casan pertenciam à Companhia de Energia Elétrica de Santa Catarina (Celesc), SC Parcerias (SCPar) e Companhia de Desenvolvimento de Santa Catarina (Codesc), todas estatais. Para executar o plano, o Executivo enviou à Assembleia um projeto de lei para abertura de capital da estatal, acompanhado de uma Proposta de Emenda Constitucional (PEC) que desobrigava a realização de prévia consulta popular, mediante alteração de controle acionário. A Assembleia aprovou a proposta para o governo estadual colocar em prática um projeto de atração de um sócio estratégico para a Casan e garantir um fundo de investimento no setor de saneamento no Estado. Os deputados aprovaram também a derrubada de uma emenda constitucional, criada em 2010, que previa a realização de um plebiscito em caso de alienação de ações da companhia. Contudo, até o final de 2015 não houve mudança na estrutura acionária da companhia. 0 Governo do Estado do Espírito Santo também decidiu abrir o capital da Cesan, Companhia Espírito Santense de Saneamento. Os deputados estaduais aprovaram, em dezembro de 2015, a abertura do capital da Companhia.
A medida é um projeto do Governo do Estado para ampliar a capacidade de investimento da estatal, com o intuito de abrir $49 \%$ do controle da empresa para investidores.

Uma outra mudança diz respeito às novas relações entre empresas privadas e companhias estaduais. A Sabesp associou-se a empresas privadas na prestação de serviços em diferentes municípios (Águas do Brasil - Cab Ambiental em Andradina, SP e Castilho, SP; Foz do Brasil - Odebrecht Ambiental em Mairinque, SP). Todos esses aspectos são indicativos de uma coalizão de interesses entre esses dois grupos de atores (companhias estaduais e empresas privadas).

Vale lembrar que, para representar seus interesses, a Abcon assumiu a representação do segmento empresarial nos Grupos de Trabalho que discutem o Plansab e questões de orçamento dentro do Conselho Nacional das Cidades.

Um outro ponto central é a aprovação da portaria n. 280, de 25 de junho de 2013, no âmbito do Ministério das Cidades, que possibilita 0 acesso de recursos do OGU, pelo setor privado, para empreendimentos de saneamento básico. 0 Conselho Nacional das Cidades, em sua Câmara Técnica do Setor, resolveu pela revogação dessa Portaria, o que não ocorreu. A Portaria altera o Manual de Instruções para Contratação e Execução dos Programas e Ações do Ministério das Cidades, inseridos no Programa de Aceleração do Crescimento PAC, aprovado pela portaria n. 164, de 12 de abril de 2013, do Ministério das Cidades. Ela visa a garantir que os recursos oriundos do PAC, destinados a ações na área de saneamento básico, possam ser aplicados em projetos de concessões comuns subsidiadas e de parcerias público-privadas. 


\section{A participação privada no setor de saneamento básico: quem são os atores principais e como se dá a participação do capital financeiro}

A Abcon estabelece, como meta, a participação privada no setor de saneamento em um patamar que atinja $30 \%$ da população, cerca de 57 milhões de brasileiros, até 2017. Verifica-se um histórico no qual grandes empresas construtoras brasileiras investiram pesadamente no setor de saneamento, através da criação de novas empresas, como Foz do Brasil (parte do Grupo Odebrecht), e a Cab Ambiental (parte do grupo Queiroz Galvão) apenas para operar nesse setor. Observando-se as empresas privadas que atuam no setor de saneamento básico, verifica-se uma mudança em sua composição de capital. Até muito recentemente as empresas mais atuantes no setor eram de capital essencialmente nacional, com origem no setor de obras públicas. Destacam-se, nesse campo, segundo a receita operacional líquida em 2015, as empresas Foz do Brasil/Odebrecht Ambiental; ${ }^{3}$ Águas do Brasil, Aegea, CAB, GS Inima. No entanto, recentemente, mudanças vêm sendo notadas, como detalhado no quadro a seguir.

No que concerne à Odebrecht Ambiental, os recursos da CEF/FGTS provêm do Programa Saneamento Para Todos que visa a financiar empreendimentos aos setores público e privado, com recursos oriundos do Fundo de Garantia do Tempo de Serviço (FGTS) e da contrapartida do solicitante. Os empréstimos têm prazos de 20 anos para as modalidades abastecimento de água, esgotamento sanitário, manejo de águas pluviais e saneamento integrado. 0 FGTS pode financiar até $95 \%$ do valor do investimento, exceto na modalidade abastecimento de água, na qual pode ser financiado até $90 \%$ do valor do investimento. As taxas de juros são de $5 \%$ ao ano, na modalidade saneamento integrado, e de $6 \%$ ao ano, nas demais modalidades. A contrapartida mínima é de $5 \%$ do valor do investimento, exceto na modalidade abastecimento de água, na qual a contrapartida mínima é de $10 \%$. A remuneração do agente financeiro correspondente ao diferencial de juros nas fases de carência e amortização, de $2 \%$ ao ano, é feita mensalmente junto com os juros contratuais, incidentes sobre 0 saldo devedor da operação de crédito. ${ }^{4}$

0 Fundo de Investimento do Fundo de Garantia do Tempo de Serviço - FI-FGTS foi criado por autorização da lei n. 11.491, de 20 de junho de 2007. Trata-se, portanto, de um fundo de investimento que não dispõe de personalidade jurídica e de estrutura administrativa e operacional próprias, com administração e gestão realizadas pela Caixa. 0 FI-FGTS tem por finalidade investir em ativos de infraestrutura no Brasil, por meio da ampliação da capacidade instalada dos setores de rodovia, ferrovia, hidrovia, porto, saneamento, energia e aeroportos, conforme seu Regulamento. 0 Fundo também poderá participar de projetos contratados sob a forma de Parcerias Público-Privadas (PPP), desde que atendidas as condições estabelecidas no Regulamento (Brasil, Ministério do Trabalho, 2016). 


\begin{tabular}{|c|c|c|c|c|c|}
\hline $\begin{array}{l}\text { Empresa / } \\
\text { aspectos de } \\
\text { interesse }\end{array}$ & $\begin{array}{l}\text { Ano de fundação e } \\
\text { áreas de atuação }\end{array}$ & $\begin{array}{l}\text { Representantes } \\
\text { formais }\end{array}$ & Locais de atuação & $\begin{array}{l}\text { Contingente } \\
\text { populacional } \\
\text { atendido }\end{array}$ & $\begin{array}{c}\text { Fontes de } \\
\text { financiamento }\end{array}$ \\
\hline $\begin{array}{l}\text { Odebrecht } \\
\text { Ambiental }\end{array}$ & $\begin{array}{l}\text { Atua desde } 2009 \text { como } \\
\text { acionista da Foz do } \\
\text { Brasil S.A.. É prestadora } \\
\text { de serviços de água } \\
\text { e esgotos. Em 2013, } \\
\text { após tornar-se sócia } \\
\text { majoritária da empresa, } \\
\text { altera sua razão } \\
\text { social para Odebrecht } \\
\text { Ambiental S.A. }\end{array}$ & $\begin{array}{l}\text { Odebrecht } \\
\text { Ambiental S.A. }\end{array}$ & $\begin{array}{l}\text { Presente em } 186 \\
\text { municípios localizados } \\
\text { em } 12 \text { estados (SP, RJ, } \\
\text { MG, ES, SC, RS, BA, TO, } \\
\text { PA, PE, GO, MA). }\end{array}$ & $\begin{array}{l}\text { Em 2015, a } \\
\text { população atendida } \\
\text { atingiu } 17 \text { milhões } \\
\text { de pessoas (Abcon, } \\
\text { Sindcom, 2015). }\end{array}$ & $\begin{array}{l}\text { CEF/FGTS (Programa } \\
\text { Saneamento Para } \\
\text { Todos), FI-FGTS, } \\
\text { BNDE[2], FNDE, } \\
\text { Debêntures. }\end{array}$ \\
\hline $\begin{array}{l}\text { Águas do } \\
\text { Brasil }\end{array}$ & $\begin{array}{l}\text { Atua desde 1995, com } \\
\text { a associação de quatro } \\
\text { empresas da área de } \\
\text { engenharia e obras } \\
\text { públicas. É líder no setor } \\
\text { de concessões privadas } \\
\text { de serviços de água, } \\
\text { coleta e tratamento de } \\
\text { esgotos. }\end{array}$ & $\begin{array}{l}\text { Developer S.A.: } \\
\text { Grupo } 100 \% \\
\text { nacional, formado } \\
\text { pela Carioca } \\
\text { Engenharia, Queiroz } \\
\text { Galvão Saneamento, } \\
\text { New Water e } \\
\text { Construtora Cowan } \\
\text { S.A. }\end{array}$ & $\begin{array}{l}\text { Estado do Rio de } \\
\text { Janeiro: Paraty, } \\
\text { Petrópolis, Araruama, } \\
\text { Saquarema, Silva } \\
\text { Jardim, Campos dos } \\
\text { Goytacazes, Niterói, } \\
\text { Resende e Nova } \\
\text { Friburgo; possui o co- } \\
\text {-controle da Foz Águas } \\
\text { 5, que opera na Zona } \\
\text { Oeste da cidade do Rio } \\
\text { de Janeiro. }\end{array}$ & $\begin{array}{l}\text { Em 2015, a } \\
\text { população atendida } \\
\text { era de aproximada- } \\
\text { mente } 5.940 .000 \\
\text { habitantes (relatório } \\
\text { da empresa) }\end{array}$ & $\begin{array}{l}\text { BNDES (Finame e } \\
\text { Finem), Itaú, Fecam, } \\
\text { Eletronuclear e } \\
\text { recursos próprios. }\end{array}$ \\
\hline Aegea & $\begin{array}{l}\text { Atua desde 2005, ano } \\
\text { da aquisição da Águas } \\
\text { Guariroba, em Campo } \\
\text { Grande -MS. É a terceira } \\
\text { maior empresa privada } \\
\text { que opera serviços de } \\
\text { água e esgotos no Brasil. }\end{array}$ & $\begin{array}{l}\text { Grupo Equivap: } \\
\text { majoritariamente } \\
\text { representado por } \\
\text { uma corporação } \\
\text { familiar; os } \\
\text { minoritários são } \\
\text { fundos vinculados } \\
\text { ao Governo de } \\
\text { Cingapura e ao } \\
\text { Banco Mundial. }\end{array}$ & $\begin{array}{l}\text { Atua em } 41 \text { municípios } \\
\text { situados em oito } \\
\text { estados: RO, PA, MA, } \\
\text { MT, MS, SP, RJ, SC. }\end{array}$ & $\begin{array}{l}5 \text { milhões de } \\
\text { pessoas atendidas } \\
\text { (site da empresa). }\end{array}$ & $\begin{array}{l}\text { Banco Mundial } \\
\text { / International } \\
\text { Finance Corporation- } \\
\text { IFC; e o BNDES. }\end{array}$ \\
\hline $\begin{array}{l}\text { CAB } \\
\text { Ambiental }\end{array}$ & $\begin{array}{l}\text { Atua desde 2006, } \\
\text { quando foi criada } \\
\text { pelo Grupo Galvão } \\
\text { Engenharia, para ser } \\
\text { gestora de concessões } \\
\text { e PPPs em serviços } \\
\text { públicos de água e } \\
\text { esgoto. }\end{array}$ & $\begin{array}{l}\text { O Grupo Galvão } \\
\text { detém o controle } \\
\text { acionário da } \\
\text { empresa; e o BNDES } \\
\text { Participações S.A. } \\
\text { detém } 33,42 \% \text { do } \\
\text { capital. }\end{array}$ & $\begin{array}{l}\text { Está presente em cinco } \\
\text { estados brasileiros: São } \\
\text { Paulo, Mato Grosso, } \\
\text { Paraná, Santa Catarina } \\
\text { e Alagoas, por meio de } \\
18 \text { operações. }\end{array}$ & $\begin{array}{l}\text { Atende, diretamente } \\
\text { ou indiretamente, } \\
\text { cerca de } 6,6 \text { milhões } \\
\text { de pessoas }\end{array}$ & BNDES \\
\hline GS Inima & $\begin{array}{l}\text { Atua desde } 1995 \text { nas } \\
\text { concessões de Limeira } \\
\text { e Ribeirão Preto. É } \\
\text { especializada em } \\
\text { atividades ambientais, } \\
\text { associadas ao } \\
\text { tratamento de água. }\end{array}$ & $\begin{array}{l}\text { Grupo de capital Sul } \\
\text { coreano que possui } \\
76 \text { filiais nacionais, } \\
\text { das quais oito são } \\
\text { de capital aberto } \\
\text { (incluindo a GS E\&C) } \\
\text { e uma rede global } \\
\text { de } 68 \text { subsidiárias } \\
\text { no exterior. }\end{array}$ & $\begin{array}{l}\text { Estado de São Paulo: } \\
\text { Campos do Jordão, } \\
\text { Mogi Mirim, Ribeirão } \\
\text { Preto, Paraibuna, Santa } \\
\text { Rita do Passa Quatro } \\
\text { e Araçatuba; e em } \\
\text { Maceió (AL). A empresa } \\
\text { atua em uma PPP com } \\
\text { a Sabesp. }\end{array}$ & & \\
\hline
\end{tabular}

Fonte: adaptado de Britto(2014). 
Segundo o relatório de 2015,

essa utilização de parte dos recursos do FGTS no mercado de capitais era uma demanda de vários agentes, inclusive organismos internacionais. Restrições regulamentares e ausência de projetos que aliassem a manutenção do papel social do FGTS com o seu direcionamento ao mercado de capitais só foram superadas com 0 início das atividades do Fl-FGTS, que criou condições de aproveitamento das oportunidades de investimento e se tornou relevante para o desenvolvimento do país. (Brasil, Ministério do Trabalho, 2016, p. 18)

Destaca-se que o FI-FGTS, enquanto fundo de natureza privada atuando como agente investidor, está exposto a riscos de mercado, de crédito e de liquidez, entre outros, conforme se lê em seu Regulamento. Na categoria ativos financeiros e/ou participações, o FI-FGTS pode realizar investimentos em diferentes modalidades: a) instrumentos de participação societária; b) debêntures, notas promissórias e outros instrumentos de dívida corporativa; c) cotas de fundo de investimento imobiliário; d) cotas de fundo de investimento em direitos creditórios; e) cotas de fundo de investimento em participações; f) certificados de recebíveis imobiliários; g) contratos derivativos; e h) títulos públicos federais (Brasil, Ministério do Trabalho, 2016).

0 Caixa Fundo de Investimento Participações Saneamento foi constituído em 6 de dezembro de 2010 sob forma de condomínio fechado, destinado exclusivamente a investidores qualificados. 0 principal objetivo do Fundo é a aquisição de participação acionária em companhias de saneamento e em projetos desenvolvidos do setor. Em dezembro de 2015, o Fundo contava com investimentos aproximados de $\mathrm{R} \$ 1,8$ bilhão em empresas do setor de saneamento, o que correspondia a 2,5\% de seu valor.

0 Caixa FIP Saneamento já realizou 0 aporte de $\mathrm{R} \$ 90,6$ milhões, em 2011, na Foz Centro Norte Participações S.A., que posteriormente alterou sua razão social para Odebrecht Ambiental - Centro Norte Participações S.A. (OACNP), resultando na aquisição de participação acionaria equivalente a $49 \%$ de seu capital social. Essa companhia é controladora direta da Companhia de Saneamento do Tocantins (Saneais) (Brasil, Ministério do TrabaIho, 2016).

A Odebrecht Ambiental recebeu também recursos do BNDES para investimentos nos sistemas de Cachoeiro de Itapemirim, Blumenau, Limeira, Rio das Ostras e Rio Claro. Também foram alocados recursos do BNDES na PPP com a Embasa para o Sistema de Disposição Oceânica do Jaguaribe em Salvador. Ela também recebeu recursos do Fundo de Desenvolvimento do Nordeste (FNDE), regulamentado em novembro de 2012.

0 FNDE destina-se a empreendimentos de interesse de pessoas jurídicas que venham a ser implantados, ampliados, modernizados ou diversificados na área de atuação da Sudene, sendo a participação de recursos na área de infraestrutura, saneamento e abastecimento de agua, áreas prioritárias, até $80 \%$ do investimento total do projeto e, nas demais áreas, 70\%. 0 Banco do Nordeste é o operador do Fundo.

Os recursos do FNDE, no valor $\mathrm{R} \$ 400$ milhões, foram disponibilizados também para investimentos da Odebrecht Ambiental em esgotamento na Região Metropolitana de Recife, na PPP assinada com a Compesa em 
2013, que abarca 15 municípios (14 municípios da RM de Recife e o município de Goiana, fora da RM) e 3,7 milhões de habitantes. Vale lembrar que, para realizar os investimentos previstos, a Odebrecht Ambiental também obteve um empréstimo da CAIXA-FGTS no valor de 700 milhões.

Em função da Operação Lava Jato, da necessidade de arrecadar $\mathrm{R} \$ 12$ bilhões, até meados de 2017, e das negociações de dívidas de empresas como a Óleo e Gás (cerca de US\$5 bilhões), a Odebrecht confirmou as mudanças na sua estrutura de negócios que incluem a Odebrecht Ambiental. A gestora canadense Brookfield comprou 70\% da Odebrecht Ambiental, por US\$768 milhões. Esta é a primeira aquisição da Brookfield, em parceria com fundos institucionais no segmento água e esgoto, e se fez através da Brookfield Brazil Capital Partners LLC e do Fundo de Investimentos BR Ambiental, ambos administrados pela canadense Brookfield Asset Management.

A Brookfield é um dos maiores grupos de investimento do mundo, atuando nas áreas imobiliária, de infraestrutura, energia renovável, construção, agropecuária e florestal; está presente em 30 países com mais de US\$250 biIhões em ativos sob gestão. 0 fechamento definitivo da transação, previsto para o primeiro trimestre de 2017, está sujeito a uma série de condições que são habituais em transações envolvendo empresas prestadoras de serviço público, como a obtenção de anuências do poder público e dos financiadores e a aprovação das

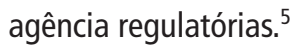

0 grupo Águas do Brasil, na PPP realizada em 2014 para os serviços de abastecimento de água e esgotamento, na área urbana de Paraty, contou com contraprestações públicas do município, do Fundo Estadual de Conservação Ambiental e Desenvolvimento Urbano (Fecam) e da Eletronuclear.

Na parceria com a Odebrecht Ambiental, a Águas do Brasil (FOZ Águas 5) assumiu os serviços de coleta e tratamento de esgoto na região Oeste do Rio de Janeiro (AP5), a segunda mais populosa AP da cidade (1,7 milhão de habitantes). 0 grupo recebeu o primeiro financiamento de longo prazo para a concessão. A Caixa Econômica Federal destinou, à empresa, R\$640 milhões por meio do programa Saneamento para Todos, via recursos do FGTS, para investimentos em um período de quatro anos (2013-2016).

0 grupo japonês Itochu tomou participação no capital da concessionária Águas do Brasil no fim de 2015, adquirindo uma parte da Queiroz Galvão, ingressando no mercado de saneamento no Brasil e se tornando um dos acionistas da empresa, que faturou $\mathrm{R} \$ 1,4$ bilhão em 2015. Vale lembrar que o Grupo faz parte do consórcio asiático formado pela Itochu Corporation, JFE Steel Corporation, Posco, Kobe Steel, Nisshin Steel e China Steel Corp, tendo também adquirido $12,48 \%$ do capital social da Congonhas Minérios, controladora da Companhia Siderúrgica Nacional (CNS), por meio de emissão primária de ações.

A Aegea, por sua vez, estruturou um modelo de gestão através do qual procura atuar como concessionária em processos nos quais ocorre a municipalização dos serviços. Sua estratégia é aposta na pulverização do mercado e no estabelecimento de longos prazos de concessão. Desde 2010, a companhia mantém um sistema de mapeamento de oportunidades nos municípios do País que se estendia até 2017 (Britto, 2014, p. 161). 
Já a Companhia de Águas do Brasil (CAB ambiental) vem diversificando sua atuação por meio de contratos de concessão e de PPP com municípios, estados e companhias públicas. Em 2008, foi assinado o primeiro contrato de PPP (CAB spat) com a Sabesp e ocorreu a entrada da empresa no estado do Paraná (Águas do Paraná). Atualmente, o Grupo está presente em cinco estados brasileiros (São Paulo, Mato Grosso, Paraná, Santa Catarina e Alagoas), por meio de 18 operações, que, somadas, atendem, diretamente ou indiretamente, a cerca de 6,6 milhões de pessoas.

Contudo, o Grupo Galvão, que controla suas ações e está entre as investigadas da Operação Lava Jato, vem avaliando a venda da concessionária de água e esgotos de Cuiabá. Os credores da CAB pressionarem a Galvão Participações (Galpar) para encontrar uma solução de mercado para o ativo, que vinha enfrentando dificuldades para cumprir os investimentos previstos nos seus contratos de concessão. Desde o ano passado a Galpar tenta, sem sucesso, vender sua participação na CAB. Em novembro de 2016, a CAB anunciou que as ações da Galpar, que está em recuperação judicial, passarão a ser de um fundo de investimentos em participação (FIP) da RK Partners. A RK Partners é um advisor independente, especializado em reorganizações empresariais, atuando em projetos de reestruturação financeira e operacional em setores variados, estando à frente de alguns dos principais e maiores processos de reestruturação empresarial realizados no Brasil. A empresa do grupo Galvão passa a ser então cotista desse fundo e acionista indireto da $C A B$ - sem perder o investimento feito na empresa. Para o fechamento da operação acontecer, existem algumas condições precedentes, dentre elas a suspensão da intervenção decretada pela prefeitura de Cuiabá na CAB Cuiabá, uma das principais concessionárias da empresa. Além disso, ficou acertado que o BNDES vai liberar os créditos já pré-aprovados com a $\mathrm{CAB}^{6}$

A GS Inima Brasil é o quinto maior conglomerado do País em termos de receita total por grupo. Possui 76 filiais nacionais, das quais oito são de capital aberto (incluindo a GS E\&C) e uma rede global de 68 subsidiárias no exterior. A subsidiária no Brasil é especializada em atividades ambientais, associadas ao tratamento de água. No Brasil ela atua por meio de empresas concessionárias (SPEs) controladas. Busca ampliar sua área de atuação de forma a implantar novas concessões e PPPs, isoladamente ou em consórcio com outras empresas. ${ }^{7}$

Em 2016, o Governo Federal lançou o Programa de Parcerias de Investimentos (PPI), coordenado pelo BNDES, com objetivo de desenvolver projetos de parcerias com iniciativa privada para a realização de investimentos em abastecimento de água e esgotamento sanitário, buscando a universalização desses serviços nos estados. Em março de 2017, o BNDES divulgou o resultado do edital que tinha por objeto a contratações de serviços técnicos especializados para processos de modelagem da privatização das seguintes companhias estaduais de saneamento: Companhia Pernambucana de Saneamento - Compesa, Companhia de Saneamento do Pará - Cosanpa, Companhia de Saneamento Ambiental do Maranhão - Caema, Companhia de Saneamento do Amapá - Caesa, Companhia de Saneamento de Sergipe - Deso e Companhia de Abastecimento de Águas e Saneamento do Estado de Alagoas - Casal. 
Encontrava-se em fase de processo licitatório a contratação dos mesmos serviços anteriores, para as seguintes companhias estaduais: Companhia de Água e Esgotos da Paraíba - Cagepa, Companhia de Águas e Esgotos do Rio Grande do Norte - Caern, Companhia de Água e Esgoto do Ceará - Cagece, Departamento Estadual de Pavimentação e Saneamento - Depasa do Acre e Companhia Catarinense de Águas e Saneamento - Casan.

Definida a modelagem, de comum acordo com cada Estado, o BNDES anunciou que continuará apoiando o processo, desde a prospecção de investidores até a realização do leilão de concessão ou de outra forma de parceria com a iniciativa privada. A política de do BNDES, para o setor de financiamento, permite financiar até $80 \%$ do projeto com taxa de juros de longo prazo (TJLP) e prazos de até 20 anos. São, evidentemente, condições que buscam atrair o investimento privado.

\section{Um contraponto: a remunicipalização dos serviços e a resistência à mercantilização}

Se, no Brasil, existe uma clara tendência de privatização dos serviços, em diferentes partes do mundo uma onda de reestatização no setor de saneamento vem se afirmando. Em 2000 foram duas remunicipalizações; em março de 2015 foram 235, em 37 diferentes países, a maioria destes, de alta renda, nos quais ocorreram 184 casos de remunicipalização ao longo dos últimos 15 anos, em comparação com 51 casos em países com renda baixa ou média. Dois países, a França, com 94 casos, e os Estados Unidos, com 58 casos, representam a grande maioria dos casos notificados em países de alta renda. Além disso, a população afetada pelos processos de remunicipalização é maior nos países de renda baixa ou média, quando comparada aos países de alta renda: 81 milhões de pessoas contra pouco menos de 25 milhões (Lobina, 2015, p. 16).

Esse processo confirma a afirmação de Swyngedouw, Kaika e Castro (2016) de que o processo de mercantilização não ocorre sem resistência; em regimes democráticos, movimentos sociais e sindicais colocaram barreiras a essas mudanças. Além disso, podemos afirmar que mesmo onde a mobilização social é mais fraca, instâncias do legislativo (tribunais) buscam intervir para garantirem o caráter público do saneamento e o direito social quando ameaçados.

Nos Estados Unidos, apesar dos esforços das empresas privadas para entrarem no setor, os serviços de abastecimento de água e esgotamento sanitário que atendem às cidades são essencialmente públicos, sendo somente $6 \%$ dos municípios americanos os que delegam a prestação de serviços a empresas privadas com fins lucrativos. Desde 2000, a remunicipalização tirou das mãos das grandes empresas de água 169 contratos. É um número significativo em relação a um contrato de gestão privada de água, se for levado em conta que as quatro mais importantes empresas privadas de água detêm cerca de $70 \%$ do mercado americano e tinham, em 2013, contratos com 760 municípios (Grant, 2015, p. 39). Mesmo no contexto de fortes pressões no sentido da privatização, cidades como Nova York, após um debate político aprofundado, têm optado por manter 0 
controle público sobre seus sistemas de água. Gandy (2002) analisa esse processo durante prefeitura do republicano Rudolf Giulianni, em uma gestão marcada pela austeridade fiscal e fortemente apoiada no setor privado. Interessante notar que a proposta de Giulianni, de venda do New York City Water Board, visava à obtenção de benefícios: pagar antigas dívidas e habilitar o município a ultrapassar os valores estabelecidos para empréstimos. Um dos opositores da venda, o City Controler ${ }^{8}$ Alan Harversi, considerou a proposta um truque fiscal com efeitos nocivos de longo termo sobre a cidade (ibid., p. 58). 0 estudo de Grant (2015) elenca as razões da opção por serviços públicos municipais nos Estados Unidos: as reduções de despesas, já que a remunicipalização permitiu, em média, uma redução de custos de $21 \%$; a busca de melhoria de desempenho, devido à falta de capacidade de resposta dos serviços privatizados e do nível insuficiente de manutenção; o controle público torna possível uma ação coordenada entre os setores da gestão urbana, permitindo uma melhor gestão dos recursos; em muitas cidades, os setores de manutenção viária e de saneamento buscam coincidir as substituições de canalização com obras viárias para evitar a duplicidade de trabalho.

Na Alemanha, em 2007, os operadores públicos de água fundaram a Aliança das Associações Públicas da Água, que buscava lutar contra a privatização e defender a gestão pública. Desde 2012, pelo menos seis cidades alemãs decidiram remunicipalizar seu serviço de água, sendo o caso mais emblemático o de Berlim. No final da década de 1990, vários de seus serviços públicos passaram para a esfera privada, incluindo a privatização parcial da prestação de serviços de água: em 1998, o governo vendeu 49,9\% das ações da companhia e $51,1 \%$ permaneceram nas mãos do setor público. Os parceiros privados eram as empresas internacionais Veolia e RWE, cada um deles tendo adquirido $24,95 \%$ das ações. Formalmente, a cidade de Berlim manteve o controle da gestão; as decisões centrais teriam de ser tomadas em uma comissão mista, na qual o governo tinha a maioria. Mas, os parceiros privados eram as forças dominantes (Herzberg, 2010, p. 204). Usando dos mecanismos disponíveis de participação, a Berliner Wassertisch ("Fórum da Água Berlim"), rede de cidadãos preocupados e comprometidos com os serviços públicos, lançou o referendo para a transparência dos contratos sobre a privatização da água. Em 13 de fevereiro de 2011, os berlinenses decidiram, por referendo, que os contratos de privatização, até então mantidos em segredo, deveriam ser publicados. Em 2012, a Agência Federal da Concorrência Alemã condenou a empresa de água de Berlim a reduzir os seus preços em $18 \%$, considerando abusivo o aumento de tarifas. Uma análise comparativa feita pela agência mostrou que as tarifas eram significativamente superiores às de outras empresas comparáveis (todas em propriedade pública). Em 2012, Berlin comprou as ações da RWE por 654 milhões de euros e, em 2013, as ações da Veolia, por 590 milhões de euros. Para fazer isso, a cidade de Berlim teve de contrair um empréstimo que deve agora ser reembolsado através de contas de água, ou seja, pelos usuários, durante um período de 30 anos. Apesar disso, como mostra Hecht, desde a remunicipalização, os investimentos em infraestrutura aumentaram, e o preço da parte da tarifa relativa ao esgotamento diminuiu (Hecht, 2015). 
Na França existe um histórico de delegação dos serviços a empresas privadas, sendo as duas principais empresas, Veolia e Suez, criadas no século XIX. Como assinala Barraqué, dos anos 1970 a 1980, muitos municípios optaram por delegar a gestão dos serviços de saneamento a empresas privadas, essencialmente porque não podiam arcar como os investimentos necessários à modernização dos sistemas (Barraqué, 2015). Esse período foi marcado por uma forte concentração da delegação dos serviços de água e saneamento a três grandes grupos envolvidos em outras áreas e também, muitas vezes, em atividades de construção: Veolia (antiga Générale des Eaux, Vivendi), Suez Environnement (antiga Lyonnaise des Eaux) e Saur. Aproximadamente $75 \%$ dos serviços municipais de água são delegados a empresas privadas e 35\% dos serviços de esgotamento sanitário. Esse aumento da delegação dos serviços foi reforçado tanto pela falta de exigência para a concorrência, como pela prática de "taxas de entrada". Esta é denominada no Brasil outorga onerosa, quando há um pagamento de um valor aos municípios permitindo que esses recursos sejam aplicados em obras ou serviços externos à água e ao esgotamento. A delegação de serviços foi também fonte de corrupção, tal como pagamentos irregulares a prefeitos para obter a concessão (Lime, 2015).

A partir do final dos anos 1990, vários fatores começaram a colocar em questão a renovação dos contratos: falta de transparência, perda de capacidade técnica e de conhecimento para monitorar o desenvolvimento de contrato, sobretudo no caso dos pequenos e médios municípios, sendo que essa perda de capacidade não pode ser totalmente compensada pelo uso de auditores externos. Houve um movimento de remunicipalização que envolveu cidades importantes, como Grenoble, Paris e Marselha. Em relatório recente sobre a situação dos serviços de abastecimento de água e esgotamento sanitário no país, a Cour des Comptes, indica que uma tendência à remunicipalização pode se consolidar em função de uma nova lei de 2015, que se refere à organização institucional, reforçando a cooperação intermunicipal e transferindo as obrigações com relação ao abastecimento de água e ao esgotamento sanitário às associações intermunicipais (communautés de communes e a communes d'agglomération). Com isso, municípios que não tinham escala nem meios para garantir uma gestão de serviços eficiente podem optar pela gestão pública consorciada dos serviços.

0 caso mais emblemático de remunicipalização na França é o de Paris, onde o processo foi iniciado na administração do prefeito eleito pela primeira vez em 2001, Bertrand Delanoé, da coalização socialista. Uma série de auditorias e revisões dos contratos com as empresas Veolia e Suez, que dividiam a prestação de serviços no município, teve início. Reeleito em 2008, o prefeito, com apoio da Câmara Municipal, decidiu remunicipalizar os serviços. A efetivação do processo ocorreu em 2010, com a criação da empresa pública Eaux de Paris.

Em entrevista, Anne Le Strat, que conduziu o processo de remunicipalização e foi presidente da Eaux de Paris, entre 2010 e 2014, afirma que: 
Eau de Paris goza de boa reputação, e com razão. Ele funciona, nós abaixamos 0 preço da água, mantendo um ambicioso programa de investimentos a longo prazo e um modelo de governança que é muito inovador em muitas áreas. Eu mesmo constatei que algumas das nossas inovações são assumidas por grupos grandes privados. (Le Strat, 2015)

Observando outros casos, em países do Sul, destacamos a cidade de Jakarta, na Indonésia. Desde 1997, quando a ditadura de Suharto ainda parecia sólida, o setor privado atua na prestação de serviços na cidade. Foi uma concessão de 25 anos, em que se firmou a gestão de distribuição de água na capital, a Thames Water (Grã-Bretanha) e Suez (França); cada uma operava os serviços em uma metade da área metropolitana: a parte Oeste é a área da PT PAM Lyonnaise Jaya (Palyja, subsidiária da Suez $51 \%$ e $49 \%$ da infraestrutura da empresa indonésia Astratel Nusantara) e a parte Leste do PT Aetra Air Jacarta (Aetra, subsidiária da empresa de Singapura Acuatico desde 2007, a empresa indonésia PT Alberta Utilities detendo $5 \%$ das ações).

A privatização da água em Jacarta foi malsucedida. A taxa de cobertura na capital da Indonésia continuou baixa, apenas 59\%; as redes estavam em mau estado, com uma taxa de perdas de até $44 \%$ - uma situação denunciada repetidamente pelo então governador. Em 24 de março de 2015, em decorrência de uma ação coletiva dos cidadãos, o Tribunal Central do Distrito de Jacarta cancelou os contratos de privatização, sendo alegada a incapacidade de gestão privada para garantir o direito humano à água aos habitantes da cidade. 0 tribunal também ordenou que o serviço de abastecimento de água fosse assumido pela empresa pública (Zamzami e Ardhianie, 2015).

\section{Considerações finais}

Buscou-se, neste texto, traçar um perfil das pressões mercantilizadoras sobre os serviços urbanos de abastecimento de água e esgotamento sanitário no Brasil, recuperando as políticas públicas implementadas entre 2007 de 2014, contrapondo-os às políticas de resistência do serviço de saneamento como serviço público, identificadas outros países.

Um primeiro aspecto a ser destacado é a política ambígua do Governo Federal nas gestões do Partido dos Trabalhadores entre mercantilização e direito. Podemos afirmar que o período em questão avançou em um marco regulatório (lei. 11.455/2007 e seu decreto de regulamentação e Plansab) que fortalece uma concepção de saneamento como direito social. Contudo, esse marco não foi suficientemente forte para frear os avanços de uma lógica de saneamento como mercadoria.

No discurso existe uma subordinação do acesso a recursos federais, a uma lógica de planejamento e controle social e fortalecimento do setor público. No entanto, isso, de fato, não ocorreu. A distribuição de recursos para obras do PAC 1 e PAC 2 exemplifica esse aspecto: ela não foi subordinada aos planos municipais; as prioridades de investimentos não foram debatidas no ConCidades e os recursos do FGTS e do BNDES foram amplamente disponibilizados para prestadores privados, fortalecendo esse setor. Mesmo nos casos onde houve concessão onerosa, como o da AP5 do Rio de Janeiro, em 
que o grupo Foz Aguas 5 transfere à Prefeitura uma parte da receita auferida, cujo destino não é transparente, a empresa recebeu um volumoso empréstimo do FGTS. Considerando os múltiplos interesses do grupo Odebrecht no município e seu envolvimento em megaprojetos de reestruturação e renovação urbanas, podemos associar essa iniciativa do grupo, apoiada pela prefeitura e referendada pelos gestores federais da política de saneamento, como inserida na prática de urbanismo neoliberal.

Observa-se, ainda, na discrepância entre o discurso e a prática a aprovação do Plansab em 2013, junto com a aprovação da liberação do acesso a recursos do PAC pelo setor privado; a constituição do FI-FGTS, Fundo de Investimento do Fundo de Garantia do Tempo de Serviço (2007) e da Caixa Fundo de Investimento Participações Saneamento (2010), assim como a atuação do BNDES através da alocação de investimentos e da ação do BNDESPar.

Considerando que a governança dos serviços de água envolve vários atores e níveis de decisão e que, embora seja materializada através dos governos, verifica-se que os atores que mais se fortaleceram no período foram os que se orientam pela mercantilização do saneamento: Cesbs de capital aberto e o setor privado, que através de seus órgãos de representação e da pressão organizada junto ao governo e junto à opinião pública através do Trata Brasil, conseguiu fazer prevalecer seus interesses.

0 fortalecimento do setor privado e da lógica de financeirização aparece nas mudanças na composição de capital das empresas privadas do setor de saneamento. Grandes grupos internacionais que têm origem no setor financeiro estão entrando, via compra de empresas ou participação acionária, nas empresas de saneamento. 0 grupo Brookfield adquiriu a Odebretch Ambiental; a Aegea, empresa privada que tem atuação em 47 municípios em diferentes estados do País, tem na sua composição acionária a International Finance Corporation (IFC), braço de crédito do Banco Mundial, o Fundo Soberano de Cingapura (GIC) e o Fundo Global de Infraestrutura (GIF), gerenciado pelo IFC. Com o Programa de Parcerias de Investimentos (PPI) do governo Temer, já iniciado pelo BNDES, a participação de grupos privados com essas características na prestação de um serviço que é um componente essencial do direito à cidade tende a se ampliar. Já foi dado início pelo BNDES ao processo de modelagem da privatização de um número importante de companhias estaduais de saneamento, sobretudo nas regiões norte e nordeste. Nessas regiões a capacidade de pagamento de tarifas de uma parte significativa dos usuários é baixa. Não estão claros os mecanismos que farão com que a gestão privada atenda a esses usuários de baixa renda.

Se o problema é garantir recursos para 0 setor e uma gestão eficiente dos serviços de saneamento, essa política merece ser questionada. Até hoje os recursos para os investimentos privados no setor não vieram dos recursos próprios das empresas, mas, majoritariamente, de fundos públicos, como o FGTS e o FAT, oriundos da contribuição dos trabalhadores, disponibilizados para o setor privado com taxas de juros bastante atraentes. 0 programa anunciado pelo BNDES parece reforçar essa tendência. Por outro lado, as experiências internacionais aqui examinadas mostram que existe uma contra 
tendência: o retorno ao serviço público municipal. As experiências de remunicipalização revelam que a gestão pública, com objetivos universalistas e não mercantis, pode ser muito eficiente, tanto em países do norte, como em países do sul.

\section{Ana Lucia Britto}

Universidade Federal do Rio de Janeiro, Programa de Pós-Graduação em Urbanismo. Rio de Janeiro, RJ/Brasil.

anabrittoster@gmail.com

\section{Sonaly Cristina Rezende}

Universidade Federal de Minas Gerais, Programa de Pós-Graduação em Saneamento, Meio Ambiente e Recursos Hídricos, Departamento de Engenharia Sanitária e Ambiental. Belo Horizonte, MG/Brasil. srezende@desa.ufmg.br

\section{Notas}

(1) http://abconsindcon.com.br/sobre-a-abcon/. Acesso em: 28 maio 2017.

(2) http://www.maxpress.com.br/Conteudo/1,446265,Abcon_avalia_pontos_criticos_do_ PlanSab,446265,7.htm. Acesso em: 28 maio 2017.

(3) Durante o primeiro semestre de 2014, a Foz do Brasil passou a se chamar Odebrecht Ambiental, o que não implicou mudança no seu corpo de acionistas, direção, escopo de atuação ou contrato com os municípios.

(4) http://www1.caixa.gov.br/gov/gov_social/municipal/assistencia_tecnica/produtos/ financiamento/saneamento_para_todos/saiba_mais.asp. Acesso em: 28 maio 2017.

(5) http://economia.estadao.com.br/noticias/geral,brookfield-compra-70-da-odebrechtambiental,10000084899; http://www.valor.com.br/empresas/4841138/odebrecht-enxugaportfolio-de-negocios-e-define-novos-lideres; http://www.valor.com.br/empresas/4824924/ estrangeiro-cresce-em-saneamento. Acesso em: 28 maio 2017.

(6) http://www.valor.com.br/empresas/4779833/cab-ambiental-reestrutura-sua-divida-e-rkpartners-entra-no-capital. Acesso em: 28 maio 2017.

(7) http://www.gsinimabrasil.com.br/pt-br/pagina/gs-inima-brasil/. Acesso em: 28 maio 2017.

(8) O City Controler é o equivalente do secretário de finanças da cidade. Com o prefeito e o procurador, ele é escolhido pelo voto popular a cada quatro anos. 


\section{Referências}

ABCON - Associação Brasileira das Concessionárias Privadas de Serviços Públicos de Água e Esgoto e SINDCON - Sindicato Nacional das Concessionárias Privadas de Serviços Públicos de Água e Esgoto (2015). Panorama da Participação Privada no Saneamento. Brasil.

AESBE - Associação Brasileira das Empresas Estaduais de Saneamento (2014). Revista Sanear, n. 23, pp. 23-24.

BARRAQUÉ, B. (2015). Dossier Régies ou délégation des services eau: dépasser les idées reçues. Environnement et technique, n. 352, pp. 43-44

BRASIL. Congresso Nacional. Lei no 11.445, de 5 de janeiro de 2007. Estabelece diretrizes nacionais para o saneamento básico. Disponível em: <www.planalto.gov.br/ccivil_03/_ato2007-2010/2007/lei/ |11445.htm>. Acesso em: 15 dez 2016.

BRASIL. Ministério do Trabalho, Fundo de Investimento do Fundo de Garantia do Tempo de Serviço (2016). Relatório de Gestão do Exercício 2015. São Paulo.

BRASIL. Ministério das Cidades. Secretaria Nacional de Saneamento Ambiental (2016). Sistema Nacional de Informações sobre Saneamento. Diagnóstico dos serviços de água e esgoto 2015. Brasília, Ministério das Cidades.

BRITTO, J. (2014). Mercado de Bens e Serviços Ambientais no Brasil -Desafios e Oportunidades. Agência Brasileira de Desenvolvimento Industrial - ABDI.

BROWN, R. E. (1976). Saúde no imperialismo: programas iniciais da Fundação Rockefeller nos Estados Unidos e no Exterior. [S.I.], A. M. J. Public Health.

BRUCKMANN, M. (2011). Ou inventamos ou erramos: a nova conjuntura latino americana e o pensamento crítico. Tese de Doutorado. Rio de Janeiro, Universidade Federal Fluminense.

CASTRO, E. (2007). Water Governance in The Twentieth-first Century. Ambiente \& Sociedade. Campinas v. X, n. 2, pp. 97-118.

COSTA, A. M. (1994). Análise histórica do saneamento no Brasil. Dissertação de Mestrado. Rio de Janeiro, Escola Nacional de Saúde Pública Sérgio Arouca.

GANDY, M. (2002). Concrete and clay: reworking nature in New York City. Cambridge, MA, The MIT Press.

GRANT, M. (2015). "L'eau entre des mains publiques: la remunicipalisation aux États-Unis". In: KISHIMOTO, S., LOBINA, E. e PETITJEAN, O. Eau publique, eau d'avenir L'expérience mondiale de la remunicipalisation. Paris, Transnational Institute (TNI), Public Services International Research Unit (PSIRU), I'Observatoire des multinationales, Municipal Services Project (MSP), la Fédération syndicale européenne des services publics (FSESP/EPSU), France Eau Publique et Aqua Publica Europea, pp. 38-47.

HECHT, C. (2015). "Les municipalités allemandes reprennent le contrôle de leur eau". In: KISHIMOTO, S.; LOBINA, E. e PETITJEAN, O. Eau publique, eau d'avenir L'expérience mondiale de la remunicipalisation. Paris, Transnational Institute (TNI), Public Services International Research Unit (PSIRU), l'Observatoire des multinationales, Municipal Services Project (MSP), la Fédération syndicale européenne des services publics (FSESP/EPSU), France Eau Publique et Aqua Publica Europea, pp. 60-67. 
HELLER, L. e CASTRO, J. E. (2007). Política pública de saneamento: apontamentos teórico-conceituais. Engenharia Sanitária e Ambiental, v. 12, n. 3, pp. 284-295.

HERZBERG, C. (2010). "Reclaims for transparency and participative revolts against oligarchisation of local democracy: lessons from public water provision in Germany. In: SINTOMER, Y.; HERZBERG, C. e HOUDRET, A. (dir.). La participation des usagers dans la gestion de l'eau avec un focus sur les rregies et entreprises municipales. Centre Marc Bloch, Ville de Paris, v. II, pp. 188-218.

HOCHMAN, G. (1996). A era do saneamento: as bases da política de saúde pública no Brasil. Tese de Doutorado. Rio de Janeiro, Instituto Universitário de Pesquisas do Rio de Janeiro.

(1998). A era do saneamento: as bases da política de saúde pública no Brasil. São Paulo, Hucitec/Anpocs.

LEONARD, J. (1993). Oswaldo Cruz y el florecimiento de la salud pública en el Brasil. Boletín de la Oficina Sanitaria Panamericana, v. 115, n. 3, pp. 222-234.

LE STRAT, A. (2015). "Retour sur la remunicipalisation de l'eau à Paris: conversation avec Anne Le Strat". In: KISHIMOTO, S.; LOBINA, E. e PETITJEAN, O. Eau publique, eau d'avenir L'expérience mondiale de la remunicipalisation. Paris, Transnational Institute (TNI), Public Services International Research Unit (PSIRU), l'Observatoire des multinationales, Municipal Services Project (MSP), la Fédération syndicale européenne des services publics (FSESP/EPSU), France Eau Publique et Aqua Publica Europea, pp. 78-86.

LIME, C. (2015). "Tourner la page de la gestion privée de l'eau en France. In: KISHIMOTO, S., LOBINA, E. e PETITJEAN, O. Eau publique, eau d'avenir L'expérience mondiale de la remunicipalisation. Paris, Transnational Institute (TNI), Public Services International Research Unit (PSIRU), I'Observatoire des multinationales, Municipal Services Project (MSP), la Fédération syndicale européenne des services publics (FSESP/EPSU), France Eau Publique et Aqua Publica Europea, pp. 68-77.

LIRA NETO (1999). O poder e a peste: a vida de Rodolfo Teófilo. Fortaleza, Edições Fundação Demócrito Rocha.

LOBINA, E. (2015). “Introduction: Pour des politiques de l'eau progressistes”. In: KISHIMOTO, S.; LOBINA, E. e PETIT JEAN, O. Eau publique, eau d'avenir L'expérience mondiale de la remunicipalisation. Paris, Transnational Institute (TNI), Public Services International Research Unit (PSIRU), I'Observatoire des multinationales, Municipal Services Project (MSP), la Fédération syndicale européenne des services publics (FSESP/EPSU), France Eau Publique et Aqua Publica Europea, pp. 12-23

LOFTUS, A. (2009). Rethinking Political Ecologies of Water. Third World Quarterly, v. 30, n. 5, pp. 953-968.

PEÇANHA, A. M. M. (1976). Um estudo de desenvolvimento institucional Separata da revista da FSESP. Dissertação de Mestrado. Rio de Janeiro, Fundação Getúlio Vargas.

REZENDE, S. C. e HELLER, L. (2008). O saneamento no Brasil: políticas e interfaces. Belo Horizonte, Editora UFMG.

RUTKOWSKI, E. (1999). Desenhando a bacia ambiental - subsídios para o planejamento das águas doces metropolitan(izad)as. Tese de Doutorado. São Paulo, Universidade de São Paulo.

SWYNGEDOUW, E. (2004). Social Power and the Urbanization of Water. Flows of Power. London, Oxford University Press. 
SWYNGEDOUW, E., KAIKA, M. e CASTRO, E. (2016). Agua urbana: una perspectiva ecológico-política. Cuadernos de Trabajo de la Red WATERLAT-GOBACIT. Serie Áreas Temáticas-AT3 SATCUASPE. EI Ciclo Urbano del Agua y los Servicios Públicos Esenciales. Cuaderno v. 3, n. 7, pp. 11-35.

ZAMZAMI, I. e ARDHIANIE, N. (2015). Aboutissement de la lutte? Les citoyens de Jakarta reprennent possession de leur service de l'eau. Eau publique, eau d'avenir L'expérience mondiale de la remunicipalisation. Paris, Transnational Institute (TNI), Public Services International Research Unit (PSIRU), I'Observatoire des multinationales, Municipal Services Project (MSP), la Fédération syndicale européenne des services publics (FSESP/EPSU), France Eau Publique et Aqua Publica Europea, pp. 48-57.

Texto recebido em 10/fev/2017

Texto aprovado em 17/abr/2017 
